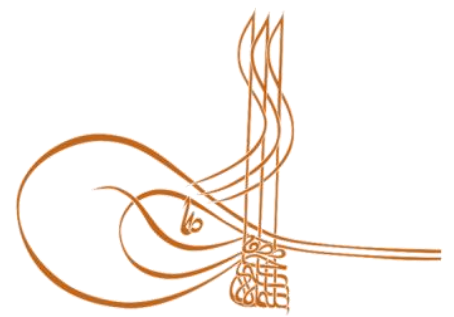

www.turkishstudies.net/economy
Turkish Studies - Economics, Finance, Politics

eISSN: $2667-5625$

Research Article / Araşttrma Makalesi

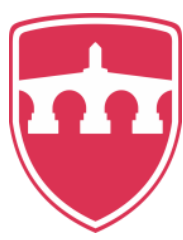

INTERNATIONAL BALKAN

UNIVERSITY

Sponsored by IBU

\title{
Küresel Bağlamda Ticaret Liberalizasyonunun Yüksek Katma Değerli Ürünlerin İhracatına Etkisi: Türkiye Örneği
}

\author{
The Effects of Global Trade Liberalization on Export of High Value Added Products: The Case of \\ Turkey
}

Salih Kalayc1*

\begin{abstract}
The trade openness is a measure of economic policies that restricts or increases trade between countries. Trade liberalization is reduction of the restrictions in terms of barriers to increase the free exchange of goods or services among countries. These barriers include tariffs such as taxes and surcharges, and non-tariff barriers such as license rules and quotas. When the current accounts in the balance of payments are taken into consideration, the main parameter is the current account deficit or the current account surplus which includes export-import difference formulated as $(\mathrm{x}-\mathrm{m})$. In the macro context, the correlation coefficient between trade liberalization process and export volume, which is the main subject of international trade, has been one of the main research topics in the academic literature. When the capital-intensive sectors and its related products of Heschker Ohlin theory are taken into account, they are the most significant income items of international trade. Therefore, trade liberalization of Turkey mostly depend on high value added product's and it's flexibility coefficient between two variables (HVAP and trade openness). For this reason, in order to calculate coefficient of correlation of two variables (HVAP and $\mathrm{f}$ trade openness) GMM method is implemented in methodology part of the research article. High value-added products (machinery, mechanical devices and instruments, nuclear reactors, other pieces) is taken from TUIK database as yearly data from 1990 to 2019. Trade openness is one of the most important indicators of trade liberalization. In this context, the findings demonstrate that if the trade liberalization (trade openness) coefficient increases, high valueadded product export is positively affected. In the light of this information, policy makers should develop a plan to gain from multilateral trade liberalization policies and try to strengthen the local market by increasing productivity in terms of high value-added production.
\end{abstract}

Structured Abstract: The trade openness is a measure of economic policies that restricts or increases trade between countries. For instance, if a country imposes a high trade tariff policy and accordingly restricts the activities of international trade, this restrictive policy prevents other countries exports and imports directly. Therefore, the lack of trade liberalization will have an economic impact that slows down economic growth.

* Dr. Öğr. Üyesi, Bursa Teknik Üniversitesi, İnsan ve Toplum Bilimleri Fakültesi, Uluslararası Ticaret ve Lojistik Bölümü

Asst. Prof. Dr., Bursa Technical University, Faculty of Humanities and Social Sciences ORCID 0000-0001-9390-9093

salih.kalayci@btu.edu.tr

Cite as/ Attf: Kalaycı, S. (2020). Küresel bağlamda ticaret liberalizasyonunun yüksek katma değerli ürünlerin ihracatına etkisi: Türkiye örneği, Turkish Studies - Economy, 15(1), 225-237. https://dx.doi.org/10.29228/TurkishStudies.40177

Received/Geliş: 15 December/Aralk 2019

Accepted/Kabul: $25 \mathrm{March} / \mathrm{Mart} 2020$

Copyright $(\subseteq$ INTAC LTD, Turkey 
Thus, decreasing the tariff have a positive impact on economic growth. In general, it is clear that neoclassical and new trade theories differ in many points, but they are in the same line that trade openness promotes economic growth among developing countries. International trade openness is a term that enables foreign direct investment, capital inflows, flow of goods and services to host countries or regions. Trade liberalization is reduction of the restrictions in terms of barriers to increase the free exchange of goods or services among countries. These barriers include tariffs such as taxes and surcharges, and non-tariff barriers such as license rules and quotas. Trade liberalization is an important part of globalization; accelerating the international trade, the growth of trade volume, the more free movement of capital, and the expansion of foreign trade relations. In this context, the fact that trade liberalization accelerates the high value-added production of countries which is an important part of doing business between regions. In the early stages of trade liberalization, one of the important phenomena of globalization is the increasing trade capacity through reforms and regulations. In fact, in the early stages of trade policy reform, trade-based tax revenues increased, mostly through lower tariffs and quotas. Free trade policies generally have positive effects on technological capacity. The impact of trade policy reform on countries' economic performance is in interaction with the adoption of new technologies and, accordingly, with parameters that increase local production capacity. The secret of successful industrialization in East Asia is definitely due to intensive investments in R \& D.

Many researchers have conducted various studies regarding the effects of trade liberalization on high value-added product's export performance. There are a large number of studies in the academic literature using different econometric techniques. According to some research results, trade liberalization has a positive effect on exports, while other studies do not indicate any significant empirical evidence. Siyakiya (2017) applied the OLS model and examined the impact of trade liberalization on low and high value-added production for 21 African countries selected for the period 1980-2014. According to the results of OLS regression, trade openness affects sectors and its markets differently. In particular, openness to foreign trade contributed to the decline in low value-added production, while at the same time finds that production capacity in sectors with high added value had a positive impact. The results of Siyakiya's (2017) study clearly coincide with the empirical findings of this article. Policy makers should develop a plan to gain from multilateral trade liberalization policies and try to strengthen the local market by increasing productivity in terms of high value-added production.

Keywords: International Trade, Globalization, GMM Method, High Value Added Products, Heschker Ohlin Theory.

Jel Codes: P33, F6, C01, L7, D24.

Öz: Ticari açıklık kavramı, ülkeler arasındaki ticareti kısıtlayan veya büyüten bir ekonomik politika ölçüsüdür. Ticaret liberalizasyonu ya da diğer tabiriyle serbestleştirilmesi, ülkeler arasında malların serbest alışverişinde kısıtlamaların veya engellerin kaldırılması veya azaltılmasıdır. $\mathrm{Bu}$ engeller, vergiler ve ek ücretler gibi tarifeleri ve lisans kuralları ve kotalar gibi tarife dışı engelleri içerir. Ödemeler dengesindeki cari hesaplar dikkate alındığında en ana parametresi (x-m) olarak formüle edilen ihracat ithalat farkından oluşan cari açık ya da cari fazladır. Makro bağlamda bakıldığında, ticarette liberalizasyonlaşma süreci ile uluslararası ticaretin en başlıca konusu olan ihracat hacmi arasındaki korelasyon katsayısı ise akademik literatürde temel araştırma konularından birisi olmuştur. Heschker Ohlin teorisinin sermaye yoğun sektörleri ve ürünleri ele alındığında uluslararası ticaret'in en önemli gelir kalemleri olarak karşımıza çıkmaktadır. Dolayısıyla, ticaret liberalizasyonu ile birlikte Türkiye'nin yüksek katma değerli üretiminin dış ticaret bağlamındaki pozitif eğilimde olan fleksibilite katsayısı GMM metodu ile birlikte hesaplanmıştır. Yüksek katma değerli ürünler (Makinalar, mekanik cihazlar ve aletler, nükleer reaktörler, bunların aksam ve parçaları) 1990-2019 dönemine ait senelik veriler şeklinde TÜİK veri tabanından alınmıştır. Ticari açıklık ise ticaret liberalizasyonun en önemli indikatörlerinden biridir. Bu kapsamda, elde edilen bulgular göstermiştir ki ticari açıklık katsayısı arttıkça yüksek katma değerli ürün ihracatı da olumlu yönde etkilenmiştir. Bu bilgiler ışığında, politika yapıcıların çok taraflı ticaret serbestleştirme politikalarından elde edilecek kazanımlara dair plan geliştirmeli ve yüksek katma değerli üretimde verim artışını sağlayarak yerel piyasanın güçlenmesi için çalışmalıdırlar.

Turkish Studies - Economy, 15(1) 
Anahtar Kelimeler: Uluslararası Ticaret, Küreselleşme, GMM Metodu, Yüksek Katma Değerli Ürünler, Heschker Ohlin Teorisi.

Jel Kodları: P33, F6, C01, L7, D24.

\section{Giriş}

Ticari açıklık kavramı, ülkeler arasındaki ticareti kısıtlayan veya büyüten bir ekonomik politika ölçüsüdür. Örneğin, eğer bir ülke yüksek ticaret tarifeleri politikası uygularsa ve buna bağlı olarak uluslararası ticaretin faaliyetlerini kısitlarsa, bu kısıtlayıcı politika diğer ülkelerin ihracat yapmasını ve söz konusu ülkeden ithalat yapmasını engelleyecektir. Ticari serbestleşmenin olmamasının, iktisadi gelișmeyi / büyümeyi yavaşlatan ekonomik bir etkisi olacaktır. Aksi durumda ise, ticari açıklığa dair toleransları arttırmanın iktisadi büyümeye olumlu anlamda etkisi olacaktır. Genel olarak, neo-klasik ve yeni ticaret teorilerinin birçok noktada farklılık gösterdiği açıktır, ancak ticaret açıklığının gelişmekte olan ülkeler arasında ekonomik büyümeyi teşvik ettiği konusunda aynı çizgidedirler. Uluslararası ticaret açıklı̆̆ 1 doğrudan yabancı yatırım, sermaye girişi, mal ve hizmetlerin ev sahibi ülke veya bölgelere akmasını sağlayan bir kavramdır. Ticaret liberalizasyonu ya da diğer tabiriyle serbestleştirilmesi, ülkeler arasında malların serbest alışverişinde kısıtlamaların veya engellerin kaldırılması veya azaltılmasıdır. Bu engeller, vergiler ve ek ücretler gibi tarifeleri ve lisans kuralları ve kotalar gibi tarife dışı engelleri içerir. Ekonomistler genellikle bu kısıtlamaların gevşetilmesini veya ortadan kaldırılmasını serbest ticareti teşvik etmek için bir adım olarak görürler. Küreselleşmenin önemli bir parçası olan ticaret liberalizasyonu; uluslararası ticaretin işleyişini hızlandırması, ticaret hacminin büyümesi, sermayenin daha da serbest dolaşımı ve dış ticaret ilişkilerinin yaygınlaşarak artışı olarak tanımlanabilir. $\mathrm{Bu}$ bağlamda, ticaret liberalizasyonunun ülkelerin iktisadi bağlamda üretim ve dağıtımını hızlandırması, ticaretin de önemli bir parçası olan yüksek katma değerli ürünler ile ilişkilendirilmesi de bu kavramın önemini açıkca göstermektedir. Küreselleşmenin önemli olgularından biri olan ticari serbestleşmenin ilk aşamalarında, reformlar sayesinde elde edilen dış ticaret artışı göreceli olarak yavaş olabilir. Aslında, ticaret politikası reformunun ilk aşamalarında, çoğunlukla yüksek tarifelerin ve kotaların düşürülmesi sayesinde ticaret temelli vergi gelirlerinde artış sağlanır. Serbest ticaret politikalarının teknolojik kapasite üzerindeki genel olarak olumlu etkileri vardır. Ticaret politikası reformunun ülkelerin ekonomik performansı üzerindeki etkisinin, yeni teknolojilerin benimsenmesinde ve buna bağlı olarak yerel üretim kapasitesini arttıran parametrelerle etkileşimi vardır.

Doğu Asya'da başarılı sanayileşme vakaları, her zaman Ar-Ge'ye yapılan yoğun yatırımlarla ilişkilendirilmiştir. Dış ticarette yoğun rekabetle yüzleşen şirketler AR-GE'ye yatırımlarını arttırma eğilimindeyse, özellikle yüksek katma değerli ürünlerin ihracatında talebi yüksek olan sektörleri hedef alan ve yerel bir teknolojik altyap1 oluşturulmasına yönelik uzun vadeli bir sanayi politikası oluşturulmalıdırlar. Akademik literatürde, bazı gelişmekte olan ülkelerin zaman içerisinde nasıl sanayileşebileceği ve katma değeri yüksek ürünler ihraç edebileceği konusunda çeşitli görüşler mevcuttur. Gelişmekte olan ülkelerin elde ettiği tecrübeler, Ricardo'nun karşılaştırmalı üstünlükler teorisi'nin uluslararası ticaret bağlamında artık rafa kalktığı düşüncesi literatürü ikiye bölmüştür (National Labor Committee, 2004).

Geçtiğimiz yüzyıl boyunca küresel ticaretin serbestleșmesi sürecinde ülkeler arasında, Dünya Ticaret Örgütü (DTÖ) müzakereleri gibi çok taraflı ticaret müzakereleri, karmaşık çok taraflı ticaret mekanizmaları, devlet uygulamalarının yetersizliği ve sert rekabetin yaşanmasından dolayı darboğaza girdiği dönemler olmuştur. Bu durumu tersine çevirmek için, Serbest Ticaret Anlaşmasına (Serbest Ticaret Bölgesi) dayanan ikili veya bölgesel serbest ticaret alanları ülkeler arasında ticaret hacmini genişletmiştir. Serbest Ticaret Bölgesi, üye ülkeler arasında işlem gören malların ve hizmetlerin çoğunda (tümü olmasa da) mal ve hizmetlerin üzerindeki tarifelerin ve 
kotaların kaldırılmasını kararlaştırmış olan bir grup ülke / ekonomi tarafından ulaşılan bir bölgesel ticaret anlaşması türü olarak tanımlanmaktadır (Yoffie, 1994).

Uzun y1llar süren durgun görüşmelerin ardından, Dünya Ticaret Örgütü Üyeleri (WTO) 2013 ve 2015 yıllarında sırasıyla Bali ve Nairobi Bakanlar Konferanslarında çok taraflı ticaretin serbestleştirilmesinde önemli ilerleme kaydetmiştir. Bali Konferansında alınan kararlar neticesinde, Ticari Kolaylaştırma Anlaşması yapılmıştır. Bakanlar tarafından alınan kararlar ve Ticari Kolaylaştırma Anlaşması sayesinde çok taraflı ticaret serbestleşmesine katkı sağlanmış ve sınır ötesi ticaret akışlarının hareketini daha da kolaylaştırmıştır. Bununla birlikte, son yıllarda bazı ülkelerde korumacı (kısıtlayıcı) ticaret önlemlerinin artması, uluslararası ticaretin işleyişine ve serbestleşmesine zarar vermiştir (Gnangnon, 2019).

Ticaretin serbestleşmesi ve küresel ekonomiye entegrasyonu, üretimi arttırmak (çıtı) ve istihdam yaratmak için firsatlar sunmaktadır. Ticaretin serbestleştirilmesi, şirketler ve sektörler arasında üretim faktörleri (emek ve sermaye) dikkate alınarak yeniden dizayn etme sürecini ortaya çıkarır. Böylece, ticaretten elde edilen gelir ise üretimde verimlilik ve süreci iyileştirme adına imkân sağlar. Hecksher Ohlin modeline göre, ülkeler iç piyasada nispeten bol olan faktörlere dair yoğun olarak kullanılan ürünleri ihraç eder ve nispeten az bulunan faktörlere dair yoğun olarak kullanan ürünleri ithal eder. Ticaret sayesinde, ihracatın genişleyeceği varsayılarak bol miktarda olan faktör talebini artıracaktır. Niteliksiz emeğin bol olduğu ve sermayenin az olduğu gelişmekte olan ülkeler, emek yoğun sektörlerle sermaye yoğun sektörler arasında denge sağlayarak, çalışanların ücret eşitsizliğini azaltacaktırlar (Aldaba, 2013).

Ticarette liberalleşmenin tarihçesine kısaca bakılacak olursa, 19. yüzy1lda sömürgelerin politika alanı, Birleşik Krallık tarafindan sömürgelerde katma değeri yüksek üretim faaliyetleri ve rekabet halindeki ürünlerin sömürgecilerin İngiltere'ye ihracat1 yasaklatılarak daha da kısıtlanmıştır. Bunun yerine, Birleşik Krallığa emek yoğun ürünlerin üretimi gerçekleştirilmiş ve ihracatı yapılmıştır. Uygulanan bu politikaların sömürgelere empoze edilmesi sonucu neticesinde, sömürgelerin sanayileşme süreçleri geciktirmiştir. Örneğin, Hindistan tekstil endüstrilerinin ihracatının yüzde 90'ından fazlası sömürge gücünün serbestleşmesinin bir sonucu olarak engellenmiştir (Shafaeddin, 2006).

Neoklasik modelin temel aldığ 1 varsayımlardan ilki emek ve sermayedir ki bir ülke için de üretim açısından olmazsa olmazdır. Devletin piyasalara müdahalesinin tam anlamıyla maksimum olduğu seviyelerde, emek ve sermaye, uluslararası pazarlarda hesaba katılan parametrelerden değildir, ekonomi dışa kapalıdır ve homojen tek bir mal üretilmektedir. Ancak, son zamanlarda, sermaye ve emek göçü, ücret farklılıklarından, güvensizlikten ve iç savaşlardan dolayı küreselleşmiş bir olgudur. Bu nedenle, böyle bir varsayım mantıksal ve teorik olarak geçersizdir ve onu destekleyecek ampirik kanıtlar da yoktur. İkincisinin ise emek ve sermaye ile birlikte üretim faktörleri göz önünde bulundurulur; sermayenin ve emeğin tamamen kullanıldığını varsayar. Bir ülkenin kaynaklarını tam olarak kullanmadığı durumlarda bile, dış ülkelerle ticaret yapmadan yurt içinde üretim ve tüketim artabilir. Ancak, tamamen kullanılmayan emek ve sermayenin uluslararası ticaretin sağlıklı işleyişi açısından doğru bir önerme olamayacağı açıktır. (Krueger, 1980).

Neoklasik iktisatçılar, Marshall-Lerner koşulunun yerine getirilmesi durumunda, yani sağlıklı kur rejiminin uygulanması ile birlikte cari açığın ortadan kalkacağına inanmaktadırlar. Ticari akışların döviz piyasalarındaki arz ve talep üzerindeki etkisine rağmen, döviz kuru, finansal faktörler gibi diğer faktörlerden ve ticari dengesizliklerden bağımsız olabilecek rasyonel ve irrasyonel beklentilerden etkilenmektedir. Cari işlemler açığının kur dalgalanması ile birlikte kompanse edilebileceği görüşü ile birlikte kaynakların serbest dolaşımı ve teknolojinin serbest elde edilmesinden kaynaklanan bazı başka parametreler de hesaba katılabilir (Rodriguez, 2006).

\section{Literatür Özeti}

Küreselleşme olgusu ticaret liberalizasyonu ve bu faktörlerin ihracat hacmine etkisi 
akademik literatürde yapılmış çok sayıdaki eserlerle ortaya konulmuştur. Değişkenlere dair kavramlar tek tek ele alındığında ise, Yirmibeşoğlu'nun (2015) makalesinde belirttiği gibi küreselleşme yeni teknolojiler ve yeni ticari ilişkiler tarafından yönlendirilen bir süreçtir. Ayrıca, bu süreç hükümetlerin, uluslararası şirketlerin, iş dünyasının ve sivil toplumun yer aldığg politik bir alandır. Küreselleşme, uluslararası mal ve hizmet ticaretini, ülkeler arasında sermaye ve emeğin serbest dolaşımını ve teknolojinin yeniden üretilmesini ve yaygınlaşmasını sağlar. Ticarette libelizasyonlaşma sürecinin de batılllaşma ve modernleşme gibi küreselleşmenin en önemli olgularından biri olduğunu belirten Yirmibeşoğlu (2015) bu kavramın sınırların ötesindeki ticarete etkisinin de medya emperyalizmi ve tüketim kültürü ile tamamlandığını ifade etmiştir.

1980'lerin ortalarında dünyada uluslararası ticaretin genel olarak serbestleşme trendine girmesinin hemen ardından önemli ölçüde iyileştirilen ihracat performansının rekabet edebilirlik rolü son yıllarda azalmışıtır. Buna ek olarak, Endonezya'daki imalat sanayisi ve ihracatının çoğunluğu, sermaye yoğun üretim yerine, vasıfsız emek yoğun imalat ürünlerine yoğunlaştığı için, ileri teknoloji katma değeri yüksek ürünlerin talep artışı nispeten daha yavaş gerçekleşmiştir (Rahmaddi ve Ichihashi, 2012).

Latin Amerika, Afrika ve Karayipler'den gelen ihracatçıların büyük ölçüde fiyat konusunda rekabet ettiklerinden ve katma değeri yüksek ürünler üretme kabiliyetlerinden yoksun olmaları nedeniyle Çin'e olan pazar paylarını kaybetmişlerdir. Kotaların kaldırılmasıyla bu ülkelerin fiyat konusunda rekabet etmeleri daha da zorlaşmıştır. ABD hükümeti 2002'de kotaları 29 kategoride kaldırdığından dolayı Çin'in pazar payı (bu kategorilerde) sadece \% 9'dan (2002) \% 65'e (2003) yükselirken, ABD perakendecilerinin Çin'den giyim için almış oldukları ürünlerin fiyatları keskin bir şekilde düşmüştür (National Labor Committee, 2004).

Hindistan'daki ticaretin serbestleşmesi ve ihracatın artması ise uzun bir döneme yayılmıştır. Ülkenin siyasi bağımsızlığından sonra ekonomik büyümesi dört döneme ayrılabilir. İlk dönem, ortalama ekonomik büyümenin \% 4,1'e yükseldiği 1951'den 1965'e kadar olan başlangıç aşamasıdır. Bununla birlikte, 1965'ten 1980'ye kadar, Hindistan, politika yapıcıların izlediği yanlış stratejilerden dolayı ekonomik durgunlukla yüzleşmiş ve bu nedenle yıllık \% 3.2'lik bir büyüme yaşamıştır. 1980'lerde ise, Hindistan yıllık \% 5 civarında bir ekonomik büyüme ile serbestleşme konusunda adeta canlanmıştır. 1990'dan sonra Hindistan dikkate değer bir ekonomik büyüme yaşamış ve yıllık \% 6.3 büyüme sağlamıştır (Tian ve Yu, 2018).

Serbest ticaret anlaşmasının üç ülke arasında en doğrudan ve belirgin ekonomik etkisi, üç ülke arasındaki bölgesel ticarette yatmaktadır. Genel Denge modeli, Çin'in ihracat, Japonya ve Kore'den yaptığ 1 ithalatın, ortalama üç eğilim gösteren politika senaryolarındaki değişim oranlarını hesaplar. İlk olarak, üç ülke arasında serbest ticaret anlaşması'nın yapılmasından sonra Çin, Japonya ve Kore arasındaki ticaret hacmi kayda değer bir şekilde artmıştır. Bunun nedeni, ticaret engellerinin çoğunun ortadan kaldırılmasından sonra, üç ülkenin birbirlerinden daha düşük maliyetlerle ürün ve hizmetleri ithal etmeleri ve ardindan artan ithalat ve ihracattan kaynaklanan talep ve arz artışına yol açmasıdır. İkincisi, Çin'in hem ihracat hem de ithalatı için, tam serbestleştirme politikası izlemesi, tahıl, tekstil ve konfeksiyon sektöründeki tarifelerin azaltılması sayesinde, ticaret hacmi daha da fazla artmıştır. Üçüncüsü, her iki senaryoda da, Çin'in Kore'ye ihracat, Japonya'nınkine oranla daha büyük oranda artarken, Çin'in Japonya ve Kore'den yaptığı ithalat, tarife seviyesindeki azalma oranlarındaki farklılık nedeniyle benzer oranlarda artmaktadır. DTÖ'nün Dünya Tarife Profilleri 2008'e göre, Kore, Çin ve Japonya tarafindan uygulanan ortalama en çok tercih edilen ülke tarife oranları sırasıyla \% 12.2, \% 9.9 ve \% 5.1'dir (Liu, Mao, Tang, Hu, ve Song, 2012).

"Serbest ticaret" düşüncesini destekleyen araştırmacılar serbestleşme yoluyla ticaretin artmasının ekonomik büyümeye ve aynı zamanda ekonominin genel gelişmesini tetikleyeceğini savunmuşlardır. Ticaretin serbestleştirilmesinin ticaretin işleyişi açısından çok önemli olduğu ve gelişmiş ülkelerin sunduğu her şeyin daha az gelişmiş ülkeler tarafından kabul edileceği genel 
olarak benimsenmiş bir düşüncedir. Araştırmacıların bu önermeleri, bir takım gerçekçi olmayan varsayımlara sahip olan Heckscher Ohlin teorisi ve karşılaştırmalı üstünlük modeline dayanır. $\mathrm{Bu}$ varsayımları görmezden gelsek bile, model, ticaretin serbestleştirilmesinin hayati koşullarını net bir şekilde ortaya koymaktadır. Bu iddiaların aksine, gelişmekte olan ülkelerin çoğunluğu, ithalat açısından düşünüldüğünde, genel olarak ekonomik büyümeyi gerçekleştirmek için katma değeri yüksek ürünlerin üretim kapasitelerini genişletir ve böylece ihracatı büyütmeye yönelik hamleler yaparlar (Shafaeddin, 2005).

Acemoğlu ve Ventura (2002) ise çalışmalarında, ticari serbestleşmenin gelişmekte olan ülkelerin yoksulluk oranlarının düşürülmesine katkı sağlayacağı, ihracatın artmasıyla birlikte gelir düzeylerinde artış olacağı ve adaletli gelir dağılımında daha da ilerleme kat edeceklerini belirtmişlerdir. Sohn'un (2001) yaptığ çalışmada, Güney Kore'nin ikili ticaret düzenlemelerini temel alarak, ticari faaliyetlerinin GSYİH's1 ile orantılı olarak artacağını veya azalacağını belirtmiştir. Bu nedenle, Güney Kore ikili ticaret faaliyetlerini genişletmek için, kendi bölgesine yakın iktisadi açıdan gelişmiş ülkelerle ticareti teşvik edecek politikalar geliştirdiklerini belirtmiştir. GSYİH faktörü göz önünde bulundurulduğunda, Güney Kore'nin ikili ticaret akışını belirlemede önemli bir etkiye sahip olmuştur. Bu durum, Güney Kore'nin ticaret modellerini miktar bazlı ürünlerin üretimi ve ihracatının pazar büyüklüğüne bağlı olarak yoğunlaştırılmış bir GSYİH modelini takip ettiği anlamını taşıdığını ifade etmiştir. Böylece Sohn (2001) makalesinde, ekonomik büyümenin en önemli göstergelerinden biri olan GSYİH ile dış ticaret hacmi arasındaki bağlantı üzerine ikili ticaret faaliyetleri geliştirilmiş devlet politikaları sayesinde, Güney Kore'nin kayda değer büyüme gerçekleştirdiğinden bahsetmiştir.

Karam ve Zaki (2019) 2013 yılında Mısır, İsrail, Ürdün, Lübnan, Fas, Tunus, Batı Şeria ve Gazze, Yemen'de faaliyet gösteren yaklaşık 30 imalat ve hizmet sektöründeki özel firmalar hakkında bilgi toplayan Dünya Bankası Kurumsal Araştırmalar veritabanını kullanmışlardır. Hizmetlerin ticaretinde serbestleşme ile marj ticareti arasındaki ilişkiyi araştırmak için, ihracat verilerinin yanısıra firma özelliklerini de araştırmışlardır. Hizmet serbestleştirme değişkeni, sektörel düzeyde hizmet ticareti kısıtlamaları endeksinin girdi çıkışı tablolarından gelen her sektördeki hizmetlerin payı ile çarpılmasıyla hesaplamışlardır. Sağlamlık kontrolleri için, ad valorem eşdeğer hizmet tarifesi, bu değişkeni oluşturmak için alternatif bir hizmet serbestleştirme ölçütü olarak kullanılmıştır. Seçim olasılığını kontrol etmek için iki aşamalı bir Heckman seçim modeli kullanılmıştır. Sonuçlar, hizmet ticareti kısıtlama önlemlerinin, marj ticareti üzerinde olumsuz bir etki yarattığını göstermiştir. Hizmet kısıtlaması, küçük firmaların uluslararası pazarlara girme ihtimalini engellemektedir ve bunun etkisi, 'motorlu taşıtlar' gibi katma değeri yüksek sektörler için oldukça önemlidir.

Zaki (2015) makalesinde, geniş çaptaki ticari serbestleştirme ve onun göstergesi olan ticari açıklı̆̆ın ikili ticaret üzerindeki etkisini ölçmüştür. Ampirik katkıları ise üç yönlüdür. Birincisi, ticari serbestleştirme özelliklerini içeren teorik bir yerçekimi modelini uygulamıştır. İkincisi, eşzamanlı olarak ticaretin serbestleştirilmesinin çeşitli yönleri dikkate alınmıştır. Üçüncüsü, yerçekimi modelinin sonuçları, ticaretteki engellerin ticaretin serbestleştirilmesi üzerindeki etkisini tahmin etmek için kullanılmıştır. İthalat faaliyetleri ise ihracat faaliyetlerine göre daha fazla olumsuz etkiye sahiptir. Sektörel özellikler göz önüne alındığında, bazı bozulabilir (yiyecek ve içecekler), mevsimlik (hazır giyim) ve katma değeri yüksek ürünlerin işlem süresinin ticaret açısından diğer sektörlere göre daha duyarlı olduğu görülmektedir. Bu sonuçlar, ticaretin serbestleşmesinin ne kadar önemli olduğunu açık bir şekilde ortaya koymaktadır. Sonuç olarak, Zaki (2015) tarafindan ticari serbestleştirme sayesinde, katma değeri yüksek ürünler ile ihracat hacmi artış oranı arasında doğru oranda korelasyon olduğu tespit edilmiştir.

Aşağıda (Tablo 1. bakınız) akademik literatürde ticaret liberalizasyonunun ihracat hacmine ve yüksek katma değerli ürünlerin ihracatına etkisi ile ilgili yapılmış çalışmalar konunun işlendiği bölge, kullanılan ekonometrik yöntem, veri yapısı, dönem aralığı ve elde edilen ampirik bulgulara 
göre tablolandırılarak sıralanmıştır. Ampirik bulguların bazıları ticaret liberalizasyonunun yüksek katma değerli ürünlerin ihracatını anlamlı derecede arttırdığını göstermiş̧ir.

Tablo 1: Ticaret Liberalizasyonunun Yüksek Katma Değerli Ürünlerin İhracatına Etkisi

\begin{tabular}{|c|c|c|c|}
\hline Yazar & Yillar & $\begin{array}{c}\text { Yöntem ve Çalışma } \\
\text { Yapılan Bölge } \\
\end{array}$ & 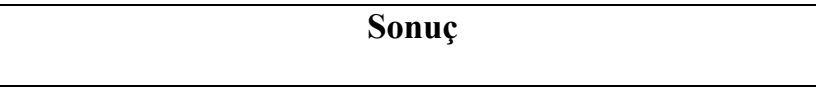 \\
\hline $\begin{array}{l}\text { Anwar, } \\
\text { Shaukat ve } \\
\text { Hussain } \\
(2010)\end{array}$ & $\begin{array}{l}1971- \\
2008\end{array}$ & $\begin{array}{lr}\text { Eş-bütünleşme } & \text { testi, } \\
\text { VAR analizi, } & \text { OLS } \\
\text { regresyon analizi. } \\
\text { Çalışlan } \\
\text { Pakistan }\end{array}$ & $\begin{array}{l}\text { Ticaret liberalizasyonu göstergeleri ile Pamuk Sargı Bezi } \\
\text { ihracatı arasında uzun vadeli ilişki tespit edilmiştir. } \\
\text { Pakistan'ın pamuk ihracatı, arz talep dengesinde daha çok } \\
\text { arz tarafını etkileyen olumlu iç politikaların } \\
\text { benimsenmesi ile geliştirilebilir. Pakistan'ın, ticaretin } \\
\text { serbestleşmesi politikalarının benimsenmesiyle } \\
\text { ihracatında kayda değer bir artış sağlayabileceği ampirik } \\
\text { olarak net bir biçimde kanıtlanmıştır. }\end{array}$ \\
\hline $\begin{array}{l}\text { Siyakiya } \\
(2017)\end{array}$ & $\begin{array}{l}1980- \\
2014\end{array}$ & $\begin{array}{l}\text { Pooled OLS modeli. } \\
\text { Çalış1lan bölge Afrika } \\
\text { ülkeleri }\end{array}$ & $\begin{array}{l}\text { Siyakiya'nın (2017) OLS modeli uygulayarak, 1980- } \\
2014 \text { dönemi için seçmiş olduğu } 21 \text { Afrika ülkesi için } \\
\text { ticari liberalizasyonun düşük ve yüksek katma değerli } \\
\text { üretim üzerindeki etkisini incelemiştir. Regresyon } \\
\text { sonucuna göre, ticari açıklığın sektörleri farklı şekilde } \\
\text { etkilediği sonucuna varmışlardır. Özellikle dış ticarete } \\
\text { açıklık, düşük katma değerli üretimin düşmesine katkıda } \\
\text { bulunurken, aynı zamanda katma değerin yüksek olduğu } \\
\text { sektörlerde yapılan üretim kapasitesinin de olumlu etkisi } \\
\text { olduğunu tespit etmişlerdir. }\end{array}$ \\
\hline $\begin{array}{l}\text { Babatunde } \\
(2009)\end{array}$ & $\begin{array}{l}1980- \\
2005\end{array}$ & $\begin{array}{l}\text { Panel en küçük kareler } \\
\text { (EKK) tahmin yöntemi } \\
\text { kullanılmıştır. Çalışılan } \\
\text { bölge Batı, Doğu, Orta } \\
\text { ve Güney Afrika }\end{array}$ & $\begin{array}{l}\text { Panel en küçük kareler (EKK) tahmin yöntemi } \\
\text { kullanılmıştır. Ek olarak, Afrikanın dört alt bölgesi (Batı, } \\
\text { Doğu, Orta ve Güney Afrika) için heterojen panellerin } \\
\text { zaman serisi kesit tekniği kullanılarak tahmin edilmiştir. } \\
\text { Ana bulgular, ticaretin serbestleştirilmesinin, marjinal ve } \\
\text { dolaylı olarak da olsa ihracat performansını etkilediği } \\
\text { yönündedir. Araştırma sonuçları göstermiştir ki ticaretin } \\
\text { serbestleştirilmesi, ithal girdilere daha fazla erişim } \\
\text { yoluyla ihracat performansını arttırmıştır. }\end{array}$ \\
\hline $\begin{array}{l}\text { Awokuse } \\
(2008)\end{array}$ & $\begin{array}{l}1993- \\
2002 \\
\text { (Çeyrek } \\
\text { dönemlik } \\
\text { veriler) }\end{array}$ & $\begin{array}{l}\text { Eş-bütünleşme testi, } \\
\text { Nedensellik testi. } \\
\text { Çalışılan bölge, } \\
\text { Arjantin Kolombiya ve } \\
\text { Peru. }\end{array}$ & $\begin{array}{l}\text { Değişkenler arası uzun vadeli ilişki tespit edilmiştir. } \\
\text { Latin Amerika ve diğer gelişmekte olan ülkeler için } \\
\text { ampirik bulguların çeşitli politik sonuçları vardır. } \\
\text { Birincisi, ekonomik büyüme stratejisi olarak ihracatı } \\
\text { teşvik etmek, ancak ithalat kısıtlamaları yapıldığında } \\
\text { kısmen etkili olacaktır. İkincisi, dışa açıklık, ihracat } \\
\text { sektöründe ihtiyaç duyulan ara üretim girdilerinin arzı } \\
\text { olarak hizmet vererek ihracatın rolünü tamamladığı için } \\
\text { ekonomik büyüme için çok önemlidir. Üçüncüsü, sınırlı } \\
\text { teknolojik donanıma sahip gelişmekte olan ekonomiler, } \\
\text { yabancı teknolojiye erişimden ve gelişmiş ülkelerden } \\
\text { elde edilen bilgiden ithalat yoluyla yararlanabilir. }\end{array}$ \\
\hline $\begin{array}{l}\text { Santos- } \\
\text { Paulino } \\
(2002)\end{array}$ & $\begin{array}{c}1972- \\
1998\end{array}$ & $\begin{array}{l}22 \text { gelişmekte olan ülke } \\
\text { için dinamik panel veri } \\
\text { analizi kullanılmıştır. }\end{array}$ & $\begin{array}{l}\text { Ticaretin serbestleşmesi ihracat performansı üzerinde } \\
\text { güçlü bir olumlu etkiye sahiptir. İhracat büyümesini de } \\
\text { yaklaşık } 2 \text { puan arttırmıştır. }\end{array}$ \\
\hline $\begin{array}{l}\text { Ratnaike } \\
\text { (2012) }\end{array}$ & $\begin{array}{l}1980- \\
2010\end{array}$ & $\begin{array}{l}\text { Panel veri analizi } \\
\text { kullanılmıştır. Çalışılan } \\
\text { bölge ise OECD } \\
\text { ülkeleridir. }\end{array}$ & $\begin{array}{l}\text { Ticaret politikalarının iç talep dinamikleri için ihracat } \\
\text { performansı konusunda büyük ölçüde önemsiz olduğu } \\
\text { tespit edilmiştir. Diğer ampirik bulgular ise OECD } \\
\text { ülkelerinde ticaret açısından liberalizasyonun ihracat } \\
\text { performansının itici gücü olduğunu göstermiştir. }\end{array}$ \\
\hline
\end{tabular}




\begin{tabular}{|c|c|c|c|}
\hline $\begin{array}{c}\text { Ahmed } \\
(2000)\end{array}$ & $\begin{array}{l}1974- \\
1995\end{array}$ & $\begin{array}{l}\text { Eş-bütünleşme testi ve } \\
\text { vektör hata düzeltme } \\
\text { modeli kullanılmıştır. } \\
\text { Çalışllan bölge ise } \\
\text { Bangladeştir. } \\
\end{array}$ & $\begin{array}{l}\text { Bangladeş için toplam ihracat ile liberalizasyon } \\
\text { politikaları için eşbütünleşme ve hata düzeltme modeli } \\
\text { uygulanmıştır. İhracat kapasitesi ve ticaret serbestleşmesi } \\
\text { arasında bir denge ilişkisi olduğu gösterilmiştir. }\end{array}$ \\
\hline $\begin{array}{l}\text { Çeştepe, } \\
\text { Y1lırım ve } \\
\text { Bahtiyar } \\
(2015)\end{array}$ & $\begin{array}{l}2000- \\
2009\end{array}$ & $\begin{array}{l}\text { Panel veri analizi } \\
\text { kullanılmıştır. Çalışılan } \\
\text { bölgeler ise Orta Doğu } \\
\text { ve Güney Afrika } \\
\text { Ülkeleridir. }\end{array}$ & $\begin{array}{l}\text { Bölgedeki ticaretin serbestleştirilmesi, yalnızca yapısal } \\
\text { uyum programları ile değil, aynı zamanda bölgesel ve } \\
\text { ikili ticaret anlaşmaları yoluyla da politik bir öncelik } \\
\text { oluşturmuştur. 2000-2009 döneminde, ticaretteki } \\
\text { engellerin kaldırılması için, Orta Doğu ve Güney Afrika } \\
\text { ülkelerinin çoğu, serbest ticaret anlaşmaları ve DTÖ } \\
\text { üyeliğinden oluşan ticari serbestleştirme politikası } \\
\text { izlemiştir. Ticaretin serbestleştirilmesi politikasının Orta } \\
\text { Doğu ve Güney Afrika ülkelerinin } 30 \text { OECD ticaret } \\
\text { ortağına ihracatı üzerindeki etkisini incelemek için panel } \\
\text { veri analizi kullanılmış ve sonuç olarak liberalleşme } \\
\text { süreci ile birlikte ticaret anlaşmalarının bu ülkelerin } \\
\text { ihracatını olumlu yönde etkilediği sonucuna varmışlardır. }\end{array}$ \\
\hline $\begin{array}{l}\text { Greenaway } \\
\text { ve } \\
\text { Sapsford } \\
(1994)\end{array}$ & $\begin{array}{l}1970- \\
1985\end{array}$ & $\begin{array}{l}\text { Çapraz kesit regresyon } \\
\text { analizi yapılmıştır. } \\
\text { Çalışılan bölgeler ise } \\
\text { Brezilya, Kolombiya, } \\
\text { Yunanistan, İsrail, } \\
\text { Kore, Yeni Zellanda, } \\
\text { Pakistan, Peru, } \\
\text { Filipinler, İspanya, Sri } \\
\text { Lanka ve Türkiyedir. }\end{array}$ & $\begin{array}{l}\text { İhracat ve ekonomik büyüme arasındaki ilişki için detaylı } \\
\text { olarak araştırma yapılmıştır. Ticaretteki } \\
\text { liberalizasyonlaşma sürecinin ekonomik büyüme ve } \\
\text { ihracat hacmine anlamlı etkisi olduğu tespit edilmiştir. }\end{array}$ \\
\hline $\begin{array}{l}\text { Abedini ve } \\
\text { Péridy } \\
(2008)\end{array}$ & $\begin{array}{l}1988- \\
2005\end{array}$ & 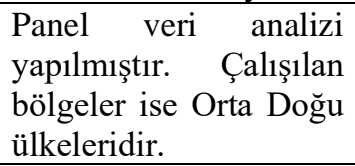 & $\begin{array}{l}\text { Büyük Arap Serbest Ticaret anlaşması, önemli ticari } \\
\text { etkiler sağlamaktadır. Sonuçlar, Büyük Arap Serbest } \\
\text { Ticaretinin uygulanmasından sonra bölgesel ticaretin \% } \\
20 \text { arttığını göstermektedir. }\end{array}$ \\
\hline $\begin{array}{c}\text { Siyakiya } \\
(2017)\end{array}$ & $\begin{array}{l}1995- \\
2015\end{array}$ & $\begin{array}{l}\text { Güney Afrika ve } 57 \\
\text { ülke için Gravite } \\
\text { modeli yapılmış ve } \\
\text { regresyon analizi } \\
\text { kullanılmıştır. }\end{array}$ & $\begin{array}{l}\text { Güney Afrika ihracatının } 1995 \text { - } 2015 \text { dönemi için } 57 \\
\text { ülkeye yapmış olduğu ihracatın ticaretteki bariyer ve } \\
\text { kota gibi kısıtlayıcı faktörler göz önünde bulundurulup } \\
\text { genel olarak analiz yapılmıştır. Sonuçlar, ithalatçı ülkeler } \\
\text { tarafından belirlenen ticaretteki bariyerlerin genellikle } \\
\text { Güney Afrika'nın tüm ürün ihracatını olumsuz yönde } \\
\text { etkilediğini göstermektedir. Bulgular, genel olarak } \\
\text { ticaretteki bariyerlerin ve kısıtlayıcı önlemlerin Güney } \\
\text { Afrika'nın ihracatını olumsuz yönde etkilediğini } \\
\text { göstermektedir. }\end{array}$ \\
\hline
\end{tabular}

\section{Metodoloji ve Veri Analizi}

Ticaret liberalizasyonunun en önemli indikatörü olan ticari açıklık verileri the Global Economy.com'un (2019) resmi sitesinden senelik veriler halinde alınmıştır. Yüksek katma değerli ürünlere ait olan senelik veriler ise TÜIK'in (2019) resmi sitesinden alınmıştır. Yüksek katma değerli ürünler ise sırasıyla Makinalar, mekanik cihazlar ve aletler, nükleer reaktörler, bunların aksam ve parçalarıdır. (Doğrudan Yabancı Yatırımcılar) DYY'ye ait senelik veriler ise Dünya Bankası'nın (2019) resmi sitesinden alınmıştır.

\section{GMM Metodu}

Ekonometride, genelleştirilmiş momentler yöntemi (GMM), istatistiksel modellerde parametreleri tahmin etmek için yapılan genel bir yöntemdir. Genelleştirilmiş momentler yöntemi (GMM), ekonomik modelin bilinmeyen parametrelerinin tahminlerini yapmak için gözlemlenen 
ekonomiye dair verileri nüfus momenti koşullarındaki bilgilerle birleştiren istatistiksel bir analiz biçimidir. $\mathrm{Bu}$ parametrelere sahip olduktan sonra, ilgilendiğimiz temel soru hakkında çıkarım yapmak için olasılık değerlerine bakılır.

GMM’ye dair değişkenler arası doğrusal ilişkiye dair denklem ise;

$$
\mathrm{g} t\left(\mathrm{w} t, \delta_{0}\right)=\mathrm{x} t \varepsilon t=\mathrm{x} t\left(\mathrm{y} t-\mathrm{z} t \delta_{0}\right) \text { şeklindenir. }
$$

$$
\begin{aligned}
& \mathrm{y} t=\mathrm{zt} \delta_{0}+\varepsilon t, t=1,,, n \\
& \mathrm{z} t=L \times 1 \text { açıklayıcı değişkenler vektörü } \\
& \delta_{0}=L \times 1 \text { bilinmeyen katsayılar vektörü } \\
& \varepsilon t=\text { rastgele hata terimi }
\end{aligned}
$$

Enstrümantal değişkenlerin ise;

$$
\mathrm{E}\left[\mathrm{g} t\left(\mathrm{w} t ; \delta_{0}\right)\right]=\mathrm{E}[\mathrm{x} t \varepsilon t]=\mathrm{E}\left[\mathrm{x} t \quad\left(y t-\mathrm{z} \quad \tau \quad \delta_{0}\right)\right]=0 \text { 'dır. }
$$

$K \times 1$ enstrümental değişkenlerin $\mathrm{x} t$ vektörünün olduğu varsayılmaktadır.

zt elementlerinin bir kısmını veya tamamını içerebilir.

$\mathrm{w} t,\{\mathrm{y} t, \mathrm{z} t, \mathrm{x} t\}$ 'un benzersiz ve sabit olmayan elemanlarının vektörünü temsil eder. $\{\mathrm{w} t\}$ 'nin durağan ve ergodik bir stokastik süreç olduğu varsayılır.

Zaman serileri kendi kendine ilişkilere sahip olabilir ve bu durumun sahte sonuçlara yol açabileceği ve endojenite problemi gösterebileceği söylenebilir. İçsellik problemini en aza indirmek için GMM tekniği uygulanmıştır. Farklı TSLS (İki Aşamalı En Küçük Kareler), White ve HAC gibi farklı GMM yöntemleri de uygulanarak TSLS yöntemi seçilerek uygulanmıştır. GMM'ye dair analiz sonuçları aşağıda gösterilmiştir.

Table 2: GMM Metodu Kök Ortalama Kare Hatası Sonuçları

\begin{tabular}{|c|c|}
\hline GMM Hata Karşılaştırma Yöntemleri & $\begin{array}{c}\text { Karekök } \\
\text { Ortalama } \\
\text { Hata } \\
\text { (RMSE) }\end{array}$ \\
\hline GMM/TSLS & $\mathbf{5 . 4 5}$ \\
\hline GMM/White & 7.16 \\
\hline GMM/HAC & 5.57 \\
\hline
\end{tabular}

Tablo 2, en düşük kök ortalama kare hatasının GMM-TSLS yöntemlerinde bulunduğunu göstermektedir. Bu nedenle, analizi yapmak için GMM-TSLS yöntemi seçilmiştir. GMM-TSLS analizine göre (Tablo 3), t-istatistik değeri 0.05 'ten fazla olduğu için, doğrulama sorunu yoktur. $\mathrm{AR}(1)$ anlamlıdır ve AR(2) anlamsızdır. Bu nedenle, zaman serilerinin parametreleri ile bu parametrelerin zaman açısından sabit bir miktar kadar önde veya geride olan parametreler arasındaki korelasyon olgusu net bir biçimde doğrulanmıştır. Ayrıca, Genelleştirilmiş Momentler 
Yöntemi - TSLS (İki Aşamalı En Küçük Kareler) modelinde Durbin Watson değeri (1.65 - Tablo 3.'e bakınız) 2'ye yakın olduğu için otokorelasyon problemi yoktur. Enstrümantal değişkenler analize eklenmiştir. Dönemsel aralıklar için de 3 kukla değişken kullanılmıştır. Kukla değişkenlerden ilki GSYH'dır ki Türkiye'nin 1990-2019 yılları için ekonomik büyüklügü̈nü gösterir. Diğer kukla değişken ise, Türkiye'nin 1990-2019 yılları için genel olarak dış borcunu gösterir. Son kukla değişken olarak da Türkiye için enerji tüketimi kullanılmıştır.

Yapılmış olan "Genelleştirilmiş Momentler Yöntemi” ele alındığında ticarette liberalizasyonlaşma süreci ${ }^{1}$ (ticaret açılığı) ve doğrudan yabancı yatırımlar'ın ${ }^{2}$ ve makinalar, mekanik cihazlar ve aletler, nükleer reaktörler, bunların aksam ve parçaları ${ }^{3}$ gibi çıktıları içeren yüksek katma değerli üretim sürecini anlamlı bir şekilde etkilemiştir. Dolayısıyla bu ampirik bulgular anlamlı ve önemlidir.

Tablo 3: GMM (Genelleştirilmiş Momentler Yöntemi)

\begin{tabular}{|c|c|c|c|c|}
\hline \multicolumn{5}{|c|}{ Bağımlı Değişken: YKDÜ (Yüksek Katma Değerli Ürünler) } \\
\hline \multicolumn{5}{|c|}{$\begin{array}{l}\text { Uygulanılan Yöntem: GMM } \\
\text { Örneklem Büvüklǚ̆̈̈: } 1990 \text { - } 2019\end{array}$} \\
\hline \multicolumn{5}{|c|}{ Örneklem Büyüklüğü: 1990 - 2019} \\
\hline \multicolumn{5}{|c|}{ Gözlem Sayısı: 30} \\
\hline \multicolumn{5}{|c|}{ Tahmini Ağırlık Matrisi: TSLS İki Aşamalı En Küçük Kareler } \\
\hline \multicolumn{5}{|c|}{ Standart Hatalar ve Kovaryans Tahmin Matrisi: C D(GSYH) D(Dis Borc) D(Enerji) } \\
\hline Değișken & $\underline{\text { Katsayı }}$ & Standart Hata & $\underline{\text { t-İstatistiğ } \mathbf{i}}$ & $\underline{\text { Olasilık }}$ \\
\hline $\mathrm{C}$ & -9857666. & 3122675. & -3.156802 & 0.0039 \\
\hline Ticaret Açıklı̆̆1 & 268720.0 & 73025.12 & 3.679830 & $\mathbf{0 . 0 0 1 0}$ \\
\hline DYY & 0.000466 & $7.94 \mathrm{E}-05$ & 5.860408 & 0.0000 \\
\hline $\mathrm{AR}(1)$ & -0.658965 & 0.315897 & -3.146568 & 0.0076 \\
\hline $\mathrm{AR}(2)$ & -0.508477 & 0.194564 & -1.684187 & 0.2056 \\
\hline R-squared & 0.243350 & & S.D. dependent var & 2.560588 \\
\hline Adjusted R-squared & -0.007800 & & Sum squared resid & 142.0789 \\
\hline S.E. of regression & 2641066. & & J-statistic & 0.140000 \\
\hline Durbin-Watson stat & 1.650911 & & $\operatorname{Prob}(J$-statistic) & 0.000000 \\
\hline Mean dependent var & 1.074572 & & & \\
\hline
\end{tabular}

Dış ticaret bağlamında liberalizasyonlaşma süreci (ticaret açıklığı) ve doğrudan yabancı yatırımlar'ın, makinalar, mekanik cihazlar ve aletler, nükleer reaktörler, bunların aksam ve parçaları gibi çıktıları içeren yüksek katma değerli üretim sürecini anlamlı bir şekilde etkilemiştir. $\mathrm{Bu}$ önemli bir bulgudur ve bu bağımsız değişkenlerin yüksek katma değerli üretim sürecine olumlu etkisi olduğu ampirik olarak kanıtlanmıştır (Tablo 3.'e bakınız). Dolayısıyla hem DYY ile YKDÜ arasında hem de ticaret liberalizasyonu ile YKDÜ arasında lineer veya doğrusal ilişki olduğu olasılık değerlerinden elde edilen sonuçlarla ortaya konulmuştur.

\section{Sonuç}

Pek çok araştırmacı, ticaretin serbestleştirilmesinin ihracat performansı üzerindeki etkisine ilişkin çeşitli çalı̧̧malar yapmışlardır. Akademik literatürde, farklı ekonometrik teknikler kullanılarak yapılmış olan çok çeşitli sayıda çalışmalar mevcuttur. Bazı araştırma sonuçlarına göre, ticaretin serbestleştirilmesinin ihracat üzerinde olumlu bir etkiye sahip olduğu, diğer çalışmalarda ise herhangi bir önemli ampirik kanıt bulunmadığı sonucuna varılmıştır.

Siyakiya'nın (2017) OLS modeli uygulayarak, 1980-2014 dönemi için seçmiş olduğu 21 Afrika ülkesi için ticari liberalizasyonun düşük ve yüksek katma değerli üretim üzerindeki etkisini incelemiştir. OLS regresyon sonucuna göre, ticari açıklığın sektörleri farklı şekilde etkilediğinin sonucuna varmıştır. Özellikle dış ticarete açıklık, düşük katma değerli üretimin düşmesine katkıda bulunurken, aynı zamanda katma değerin yüksek olduğu sektörlerde yapılan üretim kapasitesinin 
de olumlu etkisi olduğunu tespit etmiştir. Siyakiya'nın (2017) yılında yapmış olduğu çalışmanın sonuçları bu makalenin ampirik bulgularıyla net bir şekilde örtüşmektedir.

Politika yapıcılar, çok taraflı ticaret serbestleştirme politikalarından elde edilecek kazanımlara dair plan geliştirmeli ve yüksek katma değerli üretimde verim artışını sağlayarak yerel piyasanın güçlenmesi için çalışmalıdırlar. Bununla birlikte, ihracatta bir düşüş kaydedilmesinin temel nedenlerinden biri üretim süreçlerinde dış pazarlardaki iştiraklere sürekli artan bir kayma olarak gösterilebilir. Bir ülkenin ihracat performansının, ticaret serbestleşmesinden doğabilecek iç rekabetçiliğinde sağlayacağ 1 iyileşme sayesinde nispeten arttırabilir.

Ticaretin serbestleştirilmesi tarafların ticari faaliyet katsayısını arttırdığı için ihracat hacmini de arttırır. İthal edilen girdilere artan talep de kayda değer bir şekilde artar. Ayrıca, devletin ticaretin serbestleştirilmesi için etkin döviz kuru yönetimi ile belirleyici bir strateji izlemesi gerekir. Döviz kurunun değer kazanması ya da değer kaybetmesi ise diş ticaretin belirleyici parametrelerinden biri olarak karşımıza çıkmaktadır. Sabit kur rejimi benimsendiğinde ise hem enflasyon oranlarındaki belirsizlikleri bitirir hem de diş ticareti arttırabiliriz. Böylece, enflasyonu kontrol altında tutup döviz değişimlerindeki dalgalanmaları da sınırlandırmış oluruz.

Heschker Ohlin teorisi bağlamında ise ülkemizin endüstri 4.0'a tam anlamıyla geçip AR \& GE yatırımlarını arttırarak otomotiv, çelik üretimi, telekomünikasyon ve ulaştırma alanları dâhil olmak üzere daha sermaye-yoğun sektörlere yönelmesi gerekmektedir. GMM metoduyla elde edilen sonuçlara göre ticarette liberalizasyonlaşma süreci (ticaret açıklığı) ve doğrudan yabancı yatırımlar'ın ve makinalar, mekanik cihazlar ve aletler, nükleer reaktörler, bunların aksam ve parçaları gibi çıktıları içeren yüksek katma değerli üretim sürecini anlamlı bir şekilde etkilemiştir. Ticaret kısıtlamasında devletin toleransı düşük olduğunda, yüksek katma değerli üretim sürecini doğrudan etkileyerek doğrusal ilişki ortaya çıkarır. Bu bağlamda, ülkemizde düşük gümrük vergisi ve daha fazla DYY çekmek için yine düşük kurumlar vergisi uygulanmalıdır. Kaldı ki elde edilen ampirik sonuçlar göstermektedir ki DYY arttıkça yüksek katma değerli üretim de artmıştır.

Sonuç olarak, ticaret liberalizasyonunu arttırdığımızda daha fazla yüksek katma değerli ürün üretip ticaret hacmini büyüttügümüzde, cari açığı kompanse edebilir hatta cari fazla bile verebiliriz. Böylece siyasi ve iktisadi güven ortamı oluşmuş olur, kredi derecelendirme kuruluşları notlarını artıya çevirir ve buna bağlı olarak yüksek sıcak para faizi önermeden daha fazla hazine bonosu ve devlet tahvili satabiliriz. Ödemeler dengesindeki tüm kalemlerde artıya geçerek aynı know-how'ı elde etmiş Çin gibi büyük bir aktör olabiliriz.

\section{Kaynakça}

Abedini, J., \& Péridy, N. (2008). The Greater Arab Free Trade Area (GAFTA): An Estimation of its Trade Effects. Journal of Economic Integration, 848-872.

Acemoglu, D., \& Ventura, J. (2002). The World Income Distribution. The Quarterly Journal of Economics, 117(2), 659-694.

Ahmed, N. (2000). Export Response to Trade Liberalization in Bangladesh: A Cointegration Analysis. Applied Economics, 32(8), 1077-1084.

Aldaba, R. M. (2013). Impact of Trade Liberalization on Wage Skill Premium in Philippine Manufacturing (No. 2013-25). PIDS Discussion Paper Series.

Anwar, S., Shaukat, F., \& Hussain, Z. (2010). Impact of Trade Liberalization on Export of Cotton from Pakistan: A Time Series Analysis. Sarhad Journal of Agriculture, 26(2), 297-304.

Awokuse, T. O. (2008). Trade Openness and Economic Growth: Is Growth Export-Led or ImportLed?. Applied Economics, 40(2), 161-173. 
Babatunde, M. A. (2009). Can trade liberalization stimulate export performance in Sub-Saharan Africa. Journal of International and Global Economic Studies, 2(1), 68-92.

Çeştepe, H., Yıldırım, E., \& Bahtiyar, B. (2015). The Impact of Trade Liberalization on the Export of MENA Countries to OECD Trade Partners. Procedia Economics and Finance, 23, 14401445.

Dünya Bankası (2019). Foreign direct investment, net inflows (BoP, current US\$), https://data.worldbank.org/indicator/BX.KLT.DINV.CD.WD, (14.10.2019).

Gnangnon, S. K. (2019). Does Multilateral Trade Liberalization Help Reduce Poverty in Developing Countries?. Oxford Development Studies, 1-17.

Greenaway, D., \& Sapsford, D. (1994). What Does Liberalisation Do for Exports and Growth?. Weltwirtschaftliches Archiv, 130(1), 152-174.

Karam, F., \& Zaki, C. (2019). A New Dawn for MENA Firms: Service Trade Liberalization for More Competitive Exports. Applied Economics, 1-17.

Krueger, A. O. (1980). Interactions between Inflation and Trade-Regime Objectives in Stabilization Programs. NBER Working Paper, (w0475).

Liu, Z., Mao, X., Tang, W., Hu, T., \& Song, P. (2012). An Assessment of China-Japan-Korea Free Trade Agreement's Economic and Environmental Impacts on China. Frontiers of Environmental Science \& Engineering, 6(6), 849-859.

National Labor Committee. (2004). Elimination of Textile and Apparel Quotas in 2005 Will Shock the Developing World. Education Fund In Support of Worker and Human Rights. New York: NLC http://www. nlcnet. org (Accessed: 10 October 2008).

Rahmaddi, R., \& Ichihashi, M. (2012). How Do Export Structure and Competitiveness Evolve since Trade Liberalization? An Overview and Assessment of Indonesian Manufacturing Export Performance. International Journal of Trade, Economics and Finance, 3(4), 272280.

Ratnaike, Y. C. (2012). Is There an Empirical Link between Trade Liberalisation and Export Performance?. Economics Letters, 117(1), 375-378.

Rodriguez, F. (2006). Comment on Hausmann and Rodrik. Economia, 6(1), 90-98.

Santos-Paulino, A. U. (2002). Trade Liberalisation and Export Performance in Selected Developing Countries. Journal of Development Studies, 39(1), 140-164.

Shafaeddin, M. (2006). NAMA: A Tool of Development or De-industrialization? (No. 6649). University Library of Munich, Germany.

Shafaeddin, S. M. (2005). Towards An Alternative Perspective on Trade and Industrial Policies. Development and Change, 36(6), 1143-1162.

Siyakiya, P. (2017). Can Trade Openness Stimulate Output Performance? A Case of Selected African Countries. Journal of International and Global Economic Studies, 10(2), 55-6.

Siyakiya, P. (2017). The Impact of Technical Regulations on Trade: Evidence from South Africa. Journal of Economics Library, 4(1), 64-75.

Sohn, C. H. (2001). A Gravity Model Analysis of Korea's Trade Patterns and the Effects of a Regional Trading Arrangement. Korea Institute for International Economic Policy Working Paper Series, 2001, 09. 
The Global Economy (2019). https://www.theglobaleconomy.com/rankings/trade_openness/ Erişim Tarihi: 07.11.2019.

Tian, W., \& Yu, M. (2012). China and India: Trends in Trade Over the Last Decade. The Journal of China and Global Economics, 1(1), 27-38.

TÜIKK (2019). https://ticaret.gov.tr/istatistikler/dis-ticaret-istatistikleri Erişim Tarihi: 09.11.2019.

Yirmibeşoğlu, G. (2015). Globalization and International Trade. International Journal of Social Sciences and Education Research, 3(5), 1787-1796.

Yoffie, D.B. and Gomes-Casseres, B. (1994), International Trade and Competition: Cases and Note in Strategy and Management, 2nd Ed, McGraw Hill Inc.

Zaki, C. (2015). How Does Trade Facilitation Affect International Trade?. The European Journal of Development Research, 27(1), 156-185. 